\title{
Uma reflexão sobre bullying e governamentalidade a partir de três narrativas de ficção páginas
}

Juliane Bazzo (PPGAS/UFRGS)

\section{INTRODUÇÃO}

Em quaisquer sociedades, "processos civilizadores", conforme postula Elias (1997), caracterizam-se pela intrínseca instabilidade. Nunca estão dados ou acabados; pelo contrário, exigem investimentos permanentes em "autodisciplina" e "pacificação social". Coletividades e indivíduos situam-se, assim, enquanto "processos em desenvolvimento", que abrangem "graus variáveis de harmonia e conflito".

A edificação dos estados-nação ocidentais encontra-se fortemente vinculada à consolidação de um "monopólio intraestatal da força", materializado em instituições militares, policiais e tributárias. De um lado, explica Elias (id.), o êxito desse arranjo expressa-se no estabelecimento de um "tabu" razoavelmente eficaz de controle do uso irrestrito da violência física, interdito inexistente no período da Idade Média, por exemplo.

Por outro lado, "surtos descivilizadores" permanecem sempre uma possibilidade e, não raro, se manifestam com antigos ou novos contornos (id.). Tais irrupções cristalizam, nos termos de Das e Poole (2008), "margens" estatais, tanto por demarcar contextos que impulsionam o poder público a legislar e impor ordenação, quanto por abrangerem práticas sociais que, de modo desafiador, expõem a incapacidade das determinações oficiais em abarcar por completo as contingências da vida cotidiana.

Numa etnografia acerca da atuação rotineira da polícia francesa, Fassin (2013) aponta que, no cenário da pacificação das sociedades contemporâneas, enquanto as agressões físicas para além dos aparatos estatais mostraram-se objeto constantemente privilegiado de repressão e penalização, as investidas morais, cujos limites são menos palpáveis, não emergiram em mesma intensidade como alvos de controle e sanção. Desse modo, segundo o autor, a "violência moral" pôde constituir-se como uma espécie de "violência substituta". 
Quando se fala hoje em desacato moral, a palavra bullying pulula pelos discursos do dia a dia. O termo designa em língua inglesa o ato decorrente do substantivo bully, que significa algo próximo a "brigão" ou "valentão" em português. Estabelecido enquanto conceito científico nos anos 70 por Dan Olweus, professor de psicologia da Universidade de Bergen, na Noruega, o bullying alastrou-se mundialmente desde então, na função de nomear a agressividade cotidiana intimidatória, que pode ou não se transmutar em ataque físico (Rolim 2008; Bully 2011).

Graças à dispersão dos estudos de Olweus, o vocábulo passou a abarcar, primeiramente, eventos nos quais se delimitam relações de poder desiguais entre pares nos ambientes escolares, desencadeadoras de agressões especialmente morais, cuja distinção é o caráter repetido. No Brasil, o termo experimenta enorme popularização a partir dos anos 2000. A essa altura, já havia transcendido, aqui e internacionalmente, a aplicação ao universo educacional, bem como ganhado novas e modernas facetas, dentre elas, por exemplo, a de cyberbullying, o bullying praticado via meios eletrônicos $(i d .)^{1}$.

Minha pesquisa de tese de doutorado, ainda em andamento, se propõe a compreender e problematizar, desde o contexto urbano contemporâneo brasileiro, a atuação dos "empreendedores morais" (Becker 2008 [1963]) desse construto, constituídos em indivíduos, instituições, iniciativas e documentos responsáveis hoje por delimitar regramentos em torno de posturas condenatórias classificadas como bullying. Tal enfoque integra a "teoria interacionista do desvio", a qual posiciona a criação de normatizações como um "drama complexo", com desenvolvimento no tempo e implicação de uma rede cooperativa de atores, cujos interesses muitas vezes divergem.

O objetivo deste artigo $^{2}$ é lançar luz sobre tal problemática a partir de reflexões geradas pela literatura antropológica do campo da governamentalidade, com apoio de três obras ficcionais, duas delas de caráter infantojuvenil. A escolha de narrativas dirigidas a tal faixa etária deve-se ao fato de o debate social em torno do bullying originar-se e manter-se pela identificação de sociabilidades conflituosas em instituições de ensino voltadas a crianças e jovens. Dessa forma, qualquer investigação concentrada no tema do bullying, a despeito de analiticamente ter a opção discutir a dispersão de tal conceito por outros domínios para além da escola, não pode prescindir de uma reflexão em torno dos ambientes educacionais e seus públicos-alvo, dada a centralidade deles no panorama em questão.

Para tanto, a presente análise opta por posicionar o bullying enquanto um "dispositivo", noção que, conforme rememora Agamben (2005), surge na obra de Michel Foucault quando este se volta a pensar acerca do "governo dos homens" ou da "governamentalidade". Agamben explica que, embora largamente empregada por Foucault, a acepção de "dispositivo" não chegou a receber dele uma definição bem estabelecida. Diante disso, Agamben efetua um trabalho de síntese, ao propor que "dispositivo" diz respeito a um

...conjunto de práxis, de saberes, de medidas, de instituições cujo objetivo é de administrar, governar, controlar e orientar, em um sentido em que se supõe útil, os comportamentos, os gestos e os pensamentos dos homens. É algo de geral (um reseau, uma "rede") porque inclui em si a episteme, que (...) é aquilo que em uma certa sociedade permite distinguir o que é aceito como um enunciado científico daquilo que não é científico. (...) Todo dispositivo implica, com efeito, um processo de subjetivação, sem o qual o dispositivo não pode funcionar como dispositivo de governo, mas se reduz a um mero exercício de violência. (...) [O]s dispositivos visam através de uma série de 
práticas e de discursos, de saberes e de exercícios, a criação de corpos dóceis, mas livres, que assumem a sua identidade e a sua "liberdade" enquanto sujeitos no processo mesmo do seu assujeitamento. O dispositivo é, na realidade, antes de tudo, uma máquina que produz subjetivações, e só enquanto tal é uma máquina de governo. Não somente, portanto, as prisões, os manicômios, o panóptico, as escolas, as confissões, as fábricas, as disciplinas, as medidas jurídicas etc., cuja conexão com o poder é em um certo sentido evidente, mas também a caneta, a escritura, a literatura, a filosofia, a agricultura, o cigarro, a navegação, os computadores, os telefones celulares e - porque não - a linguagem mesma, que é talvez o mais antigo dos dispositivos... (ibid.:12, 10, 14-15, 13).

Em reflexão sobre as contribuições foucaultianas em torno dessa mesma ideia, Deleuze (1996) compara a empreitada de compreender um "dispositivo" à ação de cartografar: significa "caminhar por terras desconhecidas", com o intuito de desembaraçar "linhas", identificar o viés inovador, bem como a capacidade de transformação de cada um desses aparatos, tendo em vista sua não universalidade. Um "dispositivo" compõe-se assim de linhas de "visibilidade" e "enunciação", linhas de "forças" e linhas de "subjetivação". Para Deleuze, cada um desses grupos de "curvas" corresponde, respectivamente, a um dos elementos da tríade fundamental ao pensamento de Foucault (1984): "campos de saber", "tipos de normatividade" e "formas de subjetividade".

"Dispositivos" não são verdadeiros ou falsos, mas sim permeados por "jogos de verdade" que, segundo Foucault (id.), orientam-se para resultados. Com isso em mente, emerge como provocadora para a temática em debate aqui a paráfrase de uma interrogação que o autor efetua a respeito da sexualidade enquanto problema de estudo, pergunta esta que do mesmo modo caberia a seus interesses anteriores, como o crime e a loucura. A questão é a seguinte: que condições e motivações conduzem, na contemporaneidade, práticas tipificadas como bullying a se tornar "objeto de uma preocupação moral" intensificada, sob uma nomenclatura específica?

Conforme esclarece o pensador, o olhar analítico em busca de respostas deve se deslocar de uma tautologia de "interdições" para as "problematizações morais", pois estas últimas é que efetivamente contemplam a elaboração das subjetividades dos indivíduos, assim como as práticas deles em torno dos "dispositivos".

\section{INDÚSTRIA CULTURAL E GOVERNAMENTALIDADE}

Dentre as reflexões que vêm sendo empreendidas por antropólogos para pensar a questão da governamentalidade, há exemplos que lançam mão de produtos culturais massificados enquanto ferramentas analíticas e, portanto, se colocam como inspiradores à tarefa proposta pelo presente artigo. Nesse sentido, os artefatos culturais também aparecem enquanto "dispositivos", nos termos foucaultianos, ou seja, a um só tempo, como técnicas de governo e mecanismos de subjetivação.

Ortner (2007) utiliza contos de fadas dos irmãos Grimm, escritos na Alemanha do século XIX, para abordar relações entre poder, projetos e agência no que diz respeito a questões de gênero. Para ela, essas narrativas operam “... como formações culturais que constroem e distribuem agência de modos particulares, como parte da política cultural que cria pessoas apropriadamente definidas em termos de gênero em um determinado tempo e lugar" (:61). Abu-Lughod (2003), por sua vez, enxerga o melodrama televisivo como uma "tecnologia para a produção de novos tipos de pessoa" no processo contemporâneo de modernização do Egito, de maneira entrelaçada ao peso 
da tradicionalidade do parentesco e às repercussões do ressurgimento islâmico no país. Nessa mesma linha, este artigo optou por empregar enquanto recursos de análise três narrativas ficcionais, duas de perfil infanto-juvenil.

A primeira delas se intitula $A$ Ilha de Coral. Lançada originalmente em 1858, é de autoria do escocês Robert M. Ballantyne (1970), escritor dedicado à literatura para crianças e jovens, a quem se atribui a publicação de quase uma centena de livros. A I/ha de Coral tornou-se um best-seller já em sua primeira edição e alcançou o status de clássico recomendado pela Unesco (Organização das Nações Unidas para a Educação, a Ciência e a Cultura), sendo traduzido e propagado em diversos países ao longo de anos. O livro narra a aventura de três jovens marujos ingleses que, após um naufrágio, reconstroem em um território insular do Pacífico uma microssociedade organizada à moda britânica. Como pano de fundo, emerge a lógica da empreitada colonial.

Em sequência, a segunda narrativa a ser explorada é ficcional, porém, voltada ao público adulto. Trata-se de O Senhor das Moscas, publicada em 1954, considerada a obra-prima do inglês William Golding (1984), Prêmio Nobel de Literatura em 1983. Nesse livro, o autor inverte a história de $A$ Ilha de Coral, ao contar como garotos ingleses, em fuga de uma guerra, acabam náufragos numa ilha e ali se tornam "selvagens". Nesse processo, um elementochave é a intimidação moral - aos moldes do chamado bullying na atualidade - do personagem Porquinho, que encarna e defende o estilo de vida europeu no território desconhecido 3 .

Por fim, a terceira narrativa se chama Filhote de Cruz-credo: a triste história alegre de meus apelidos, assinada pelo escritor gaúcho Fabrício Carpinejar (2014). Trata-se da obra que subsidiou ações realizadas na rede pública escolar gaúcha, ao longo de 2014, pelo projeto "Educar sem Discriminar", lançado um ano antes pelo Governo do Rio Grande do Sul, para prevenção ao bullying entre crianças e adolescentes. Como aporte contextual a essa iniciativa, importa destacar que o Rio Grande do Sul situa-se entre os estados brasileiros pioneiros a criar uma legislação específica de combate ao bullying em instituições de ensino (Lei ordinária 13.474/10)4.

As narrativas selecionadas têm como ponto comum o fato de falarem acerca de "processos civilizadores", nos termos de Elias (1997). A partir dessa aproximação e por intermédio do exercício comparativo, a ideia é iluminar, como dito, a problematização do bullying na atualidade enquanto um "dispositivo", no sentido foucaultiano já debatido. Isso se dará por dois caminhos.

De um lado, por meio do cotejo de dois modelos de governamentalidade: um pertencente ao século XIX, de viés normalizador, presente em $A$ I/ha de Coral e outro vinculado ao século XXI, de caráter neoliberal, situado em Filhote de Cruz-credo. Esses dois modelos apontam, por conseguinte, para duas molduras deveras diferentes de subjetivação. De outro lado, do mesmo modo que $O$ Senhor das Moscas coloca o "dedo em algumas feridas" (Silva 2008) e assim explicita limites da empreitada etnocêntrica inglesa, a aspiração é abordar alguns pontos de descentramento resultantes do investimento etnográfico em torno do empreendimento moral do bullying na contemporaneidade, algo que venho desenvolvendo no âmbito de meu doutoramento.

O itinerário do trabalho de campo da tese de doutorado está organizado a partir da noção de "campo" de Bourdieu (2003a, b), com o intuito de dar conta da realização de uma etnografia de experiências "multissituadas" (Marcus 1995; Hannerz 2003), demandada pela temática em questão. Um dos campos já em acompanhamento 
mais avançado tem sido o midiático, especialmente por funcionar como uma rica fonte de dados para abastecer a problematização de outros campos vislumbrados para a etnografia: o educacional, o estatal, o científico e o mercadológico.

Diante disso, sob inspiração do desvelamento provocado pela obra $O$ Senhor das Moscas, a intenção aqui é problematizar antropologicamente o bullying conectando elementos presentes na narrativa de Filhote de Cruzcredo a reflexões oriundas da etnografia que venho realizando no campo midiático. Tal universo compreende tanto conteúdo advindo da imprensa oficial, como aquele resultado de mídias colaborativas 5 .

\section{PRIMEIRA NARRATIVA: A ILHA DE CORAL}

As aventuras de $A$ Ilha de Coral (Ballantyne 1970 [1858]) são contadas pelo ponto de vista de Rodolfo Rover, um jovem inglês que, aos 15 anos, decide realizar a viagem dos seus sonhos num barco da marinha britânica, em direção a ilhas espalhadas pelos mares do Pacífico, objetos da empreitada colonial. Ele seguia, assim, os passos do avô e do pai, que também haviam sido marujos. Na embarcação, o protagonista conhece outros dois rapazes, Juanito Martin e Peterkin Gay, com quem estabelece laços de amizade. A certa altura da viagem, ocorre uma grande tempestade, a qual provoca um naufrágio responsável por dizimar toda a tripulação, exceto os três garotos, que conseguem nadar até um território insular próximo, aparentemente deserto.

Enquanto aguardam ser resgatados, os meninos imprimem grande esforço em reconstruir na ilha uma vida semelhante àquela levada em meio à "civilização". Seus conhecimentos de jovens marinheiros é que vão Ihes permitir usar dos elementos naturais disponíveis para assegurar a sobrevivência. Ao longo dos dias, eles elaboram instrumentos de caça, proteção e locomoção, além de coletar frutos abundantemente presentes na ilha. Nesse sentido, fazer uma fogueira para obter luz coloca-se como primeira preocupação, não apenas por segurança ou conforto alimentar. O narrador relata em um trecho: "Peterkin foi logo dizendo que crua ou cozida qualquer comida era suportável, mas que não era bicho do mato para jantar no escuro" (:26).

Uma vez implementada a fogueira, eles organizam um acampamento e estabelecem uma rotina disciplinada de trabalho, especialmente em torno da construção de um bote, com o intuito de poder navegar e explorar os arredores. Nesse ínterim, preocupam-se em contar os dias, de modo a descansar aos domingos. A despeito do calor e da umidade, empenham-se em se manter adequadamente vestidos e calçados. $E$, em certo momento, o grupo ganha um novo companheiro: um gato selvagem. Encontrado ferido, o animal recebe cuidados e acaba domesticado pelos garotos.

Apesar das circunstâncias fatídicas, não esmorece no cotidiano a conexão dos jovens com instituições as quais a narrativa confere destaque: o Estado, a família e a igreja. Em um trecho, expõe Rodolfo:

Pensei no meu país, na família, nos amigos e pedi fervorosamente a Deus que nos concedesse a graça de revê-los. Só em ocasiões assim, longe da pátria e do lar, é que percebemos o amor que lhes dedicamos; atenuados pela ausência até os defeitos ingleses me pareciam adoráveis. (:111) 
Numa dada altura da narrativa, após andanças pelo território da ilha, os rapazes descobrem uma cabana abandonada, onde em uma cama jazem os esqueletos de um homem e de um cachorro, que eles se preocupam em enterrar dignamente, segundo seus padrões de civilidade. Ademais, encontram nesse espaço uma pistola que, a princípio, os anima, mas logo a constatam desativada. A atenção às armas é uma constante durante toda a história, tendo em vista que os meninos temem ser mortos por "selvagens sanguinários" daquela região, sobre os quais já tinham ouvido muito falar em seu país.

O encontro com os nativos do lugar se dá no meio da narrativa, quando dois grupos rivais locais desembarcam na ilha para uma batalha. Diante da chegada deles, os garotos se assustam e rapidamente se escondem no meio da mata. A primeira descrição do narrador sobre os "selvagens" é a seguinte: "Eram escuros e robustos, estavam quase totalmente nus e mais pareciam demônios que seres humanos" (:101).

No decorrer da história, seguem-se vários episódios de encontro com os nativos e, dentre as práticas deles a causar estranhamento entre os rapazes ingleses, uma lhes parece mais chocante: o canibalismo. Acerca do momento em que assistia, escondido na floresta, ao desenrolar da referida batalha entre os "selvagens", Rodolfo relata:

De repente, um dos selvagens desfechou um terrível golpe na cabeça do prisioneiro (...). Depois de o matarem, os canibais cortaram-lhe o corpo em pedaços, assaram-nos ligeiramente e começaram a devorá-los. Desviamos a vista, tomados de horror e repugnância, diante do bárbaro espetáculo. (...) Mais tarde, viemos a saber que os selvagens devoravam apenas os inimigos mais valentes, pois pensavam adquirir assim suas qualidades. Um método um tanto estranho para nossa compreensão, mas no qual acreditavam piamente. $(: 102,109)$

Como se percebe, a lógica colonialista aparece imiscuída à obra como um todo. Findo o mencionado confronto entre os aborígenes, os garotos sensibilizam-se e decidem libertar os cativos mantidos vivos pelo grupo vencedor. Desse ato, decorre um novo enfrentamento, o qual os jovens ingleses finalizam como heróis: “Terminada a batalha, os selvagens que havíamos libertado nos rodearam, admirados e respeitosos..." (:106).

Ademais, o papel das missões religiosas é exaltado no livro em diversas ocasiões, como meio de tornar os nativos daquela região cristãos, pacíficos e "dignos de confiança". A ótica colonial também se revela nas várias passagens em que o protagonista se refere ao território insular como "nossa ilha". Em um momento, ele relembra uma fala de Peterkin: "Acho tudo muito bacana (...) - [t]emos uma ilha só para nós e vamos governá-la a nosso modo" (:20).

Por fim, nos últimos episódios da narrativa, há ainda uma outra referência interessante ao ímpeto imperialista. Após ser capturado por piratas, Rodolfo consegue fugir num barco tomado dos saqueadores, com o qual apanha seus amigos e segue com eles a caminho da Inglaterra. Já longe dos piratas, em direção à ilha, ele investiga os recursos disponíveis na embarcação e conta: "Só encontrei um livro no barco: As viagens do Capitão Cook. Li esse livro admirável com sofreguidão e ele foi de grande utilidade no transcurso dessa viagem, prestando-me vários esclarecimentos sobre navegação" (:160, grifo do original) ${ }^{6}$. 
Embora relate sentimentos de temor, de modo geral, a história enfatiza a coragem e o companheirismo do trio de personagens em desbravar e domar o território insular. Na narrativa, a violência volta-se sempre ao desconhecido: às ameaças do ambiente natural, ao modo de vida canibal dos "selvagens" e à truculência dos piratas. A despeito da tensa conjuntura, a agressividade não emerge, em nenhum momento, na relação entre os garotos que, em diversas passagens, surgem retratados enquanto amigos felizes, como se estivessem em "férias". A jocosidade é um elemento central no relacionamento, porém, nunca chega perto de desencadear brigas, sejam verbais ou físicas, entre os conterrâneos.

Todos esses detalhes de $A$ Ilha de Coral são trazidos à baila porque costuram um bom pano de fundo para visualizar, nos termos de Foucault (1979), uma "sociedade de governo" consolidada na era vitoriana, período de auge da investida colonial, do crescimento demográfico e da industrialização na Inglaterra, quando a referida obra infanto-juvenil foi lançada. Segundo Foucault, esse modelo de coletividade, pautado por táticas e técnicas de governo, tem bases lançadas a partir de meados do século XVIII e vem agudizar no Ocidente elementos de arranjos anteriores. Dentre eles, destacam-se o "problema do fundamento da soberania" e a "necessidade de desenvolver disciplina" no interior dos estados nacionais, por meio de instituições como a família, a igreja, a escola, as oficinas de trabalho, o hospital, o quartel, a prisão, etc.

A "sociedade de governo" ou "sociedade de normalização" possui como marco a "emergência do problema da população". De acordo com Foucault (2005), o surgimento de tal noção está intrinsecamente conectado aos avanços da ciência, que propiciaram à medicina ampliar, de modo sem precedentes, a capacidade de intervenção sobre a expectativa de vida. Nesse quadro, postula o pensador, conforma-se uma "biopolítica", que "... lida com a população (...) como problema a um só tempo científico e político, como problema biológico e como problema de poder..." (ibid.:292-293).

Nesse panorama de "biopoder", em que a vida do homem enquanto espécie desponta como valor supremo, a prática da violência e o status da morte adquirem novas feições, pela via de um racismo operacionalizado por clichês evolucionistas. Foucault (id.) explica que, no século XIX, as teorias darwinianas, uma vez imersas no senso comum, configuraram "... uma maneira de pensar as relações da colonização, a necessidade das guerras, a criminalidade, os fenômenos da loucura e da doença mental, a história das sociedades com suas diferentes classes, etc." (ibid.:307).

Por intermédio desse sustentáculo, a eliminação da alteridade indesejada, especialmente aquela marcada pela raça, se situa não enquanto uma ideologia, mas sim uma "tecnologia de poder", que passa a permitir ao Estado exercer sua soberania, ao mesmo tempo que propicia a cada cidadão “... fortalecimento biológico da própria pessoa na medida em que ela é membro (...) de uma população, na medida em que se é elemento de uma pluralidade unitária e viva" (ibid.:308). Tal vínculo pátrio e sua relação de superioridade e dominância para com o "outro" encontram clara expressão em $A$ Ilha de Coral, na postura dos três jovens marujos diante dos "selvagens" habitantes do território insular. 


\section{SEGUNDA NARRATIVA: O SENHOR DAS MOSCAS}

"Não seria uma boa ideia escrever um livro sobre crianças em uma ilha, mas que se comportassem exatamente como o fariam na vida real, e não como os adultos pensam que se comportariam?" (Golding 1984: 7). Tal indagação, exposta por William Golding durante uma entrevista, integra o contexto no qual nasceu o romance mais notório desse escritor inglês. Golding, que serviu a marinha britânica na segunda guerra mundial, conta que, passado o conflito, vivia num pequeno apartamento com a esposa e os filhos. A fim de entretê-los, o casal costumava ler obras infantis, muitas das quais tinham ilhas enquanto cenários. Nessa atmosfera, o autor dirigiu à sua mulher a questão antes mencionada. E assim voltou-se à escrita de $O$ Senhor das Moscas, publicado em 1954, um século depois de $A$ llha de Coral.

Golding elabora uma história que se apropria da moldura narrativa desse clássico infanto-juvenil, porém, Ihe inverte profundamente os elementos e os sentidos. Em O Senhor das Moscas, um grupo de escolares de até 12 anos se vê numa ilha deserta do Pacífico, após a queda do avião no qual fugiam, oriundo de uma cidade vítima de um bombardeio atômico. Não há nenhum adulto sobrevivente entre eles, de modo que, sozinhos, precisam dar conta de sua subsistência. De saída, os garotos estabelecem alguma ordenação. Concordam no início: “Precisamos ter regras e obedecer a elas. Afinal, não somos selvagens. Somos ingleses e os ingleses são melhores em tudo" (:45).

Eles encontram uma grande concha e determinam que, quem está com ela em mãos, tem o direito de fala. Por intermédio desse mecanismo, organizam a eleição democrática de um líder. O vencedor é Ralph, um garoto mais velho, que supera outro de idade próxima, cujo nome é Jack. Fica decidido que este último, líder de um coro religioso antes do desastre aéreo, continuaria à frente desse grupo, cuja atribuição, a partir de então, seria conduzir caçadas, de maneira a alimentar o coletivo. A despeito da divisão de poderes, instaura-se nesse momento uma rivalidade entre ambos, que dá o tom da narrativa até o fim.

Muito logo, tal quadro de estabilidade precária começa a se deteriorar, tendo em vista que uma rotina de trabalho e de descanso em torno de um acampamento, como os jovens a princípio desejavam, não consegue ser por eles elaborada. Uma fogueira é acesa, mas por falta de cuidado, ora não se mantém, ora se expande demais. A ingestão de frutos da ilha causa distúrbios intestinais e espaços indevidos se tornam áreas de defecação indiscriminada. Há um medo generalizado, especialmente entre os menores, diante de um "bicho" que dá sinais noturnos de presença na ilha. O clima é de tensão e provocação constantes.

A grande ruptura se configura quando Jack decide criar seu próprio grupo e consegue levar com ele quase todos os garotos. Eles se estabelecem numa área diferente da ilha e tornam as caçadas aos porcos o centro de seu cotidiano. Para tanto, pintam o corpo e entoam gritos guerreiros: "Matem o porco! Cortem a garganta! Tirem o sangue!" (:77). O narrador onisciente então afirma: “Compreendiam muito bem a liberdade para a selvageria representada pela pintura" (:172).

A certa altura, Jack e seus companheiros decidem espetar em uma estaca a cabeça de um porco abatido, a fim de ofertá-la ao "bicho" que lhes assusta, de modo a mantê-lo calmo. No meio da mata, rodeada de insetos, tal 
oferenda é o elemento a fazer conexão metafórica com o título do livro: “Senhor das Moscas", tradução do termo hebraico Belzebu (Silva 2008). O personagem Simon, criança mística da narrativa, tem um encontro com o Senhor das Moscas na floresta, durante o qual vive uma espécie de transe, premonitório dos trágicos acontecimentos que, muito em breve, acometeriam o coletivo de garotos (Santos 2013).

Ao sair da mata, em meio a uma tempestade noturna, Simon encontra na praia o grupo de Jack, numa festa em torno de uma próspera caça recém-obtida. Com a visão dificultada pela forte chuva, os meninos creem que Simon seja o bicho e acabam por assassiná-lo. Antes de consumar o homicídio, entoam: "Matem o bicho! Cortem a garganta! Tirem o sangue! Acabem com ele!" (:153). O corpo termina levado pela maré.

Há ainda mais um assassinato na história, do personagem chamado Porquinho, no qual gostaria de me deter adiante. Quando Jack forma seu próprio grupo, ficam do lado de Ralph apenas algumas crianças menores e Porquinho, um garoto obeso, asmático e que enxerga mal. Em virtude de tais características, ele é tripudiado por todos ao longo da narrativa. Os gracejos começam logo na chegada à ilha:

- Não me importo como me chamam - disse confidencialmente [Porquinho] -, desde que não me chamem do mesmo jeito que na escola.

Ralph interessou-se levemente.

- Como era?

O menino gordo deu uma olhadela por sobre o ombro, depois inclinou-se para Ralph. E cochichou.

- Me chamavam de "Porquinho".

Ralph explodiu numa gargalhada. Levantou-se num salto.

- Porquinho! Porquinho!

- Ralph... por favor!

Porquinho esfregava as mãos, de tanto desespero.

- Eu disse que não queria...

- Porquinho! Porquinho! (:15)

Ralph espalha o apelido, lembrado sempre que Porquinho tenta conferir ordem à caótica vida coletiva dos garotos. Porquinho corporifica a racionalidade e a civilidade na narrativa (Silva 2008; Belo 2011; Botelho 2012; Santos 2013). Em certo momento, por exemplo, ele diz: “Aposto que já é hora do chá (...). Que pensam fazer naquela montanha?" (:41). Em outro trecho, repreende os garotos: “O que somos? Humanos? Ou animais? Ou selvagens? O que os adultos irão pensar? Ir de qualquer jeito... caçar porcos... deixando a fogueira apagar... e agora!" (: 93). Ao que alguém responde: "Cale a boca, sua lesma gorda!" (id.).

A morte de Porquinho, dessa forma, vai se dando muito antes de seu homicídio propriamente dito, por sucessivas violações morais, que o vão transformando em "outro", estrangeiro ao grupo. Diz o narrador:

Porquinho era um chato, sua gordura, sua asma e suas ideias vulgares eram uma chatura. Mas sempre havia um pequeno prazer em zombar dele, mesmo que de modo acidental. (...) Os [garotos] grandes haviam chegado à opinião tácita de que Porquinho era um estranho, não só pelo sotaque, o que realmente não tinha importância, mas também pela gordura, pela asma, os óculos e certa aversão pelo trabalho manual. (:67) 
Nesse contexto, o assassinato de Porquinho é precedido por dois acontecimentos dignos de nota. O primeiro situa-se no roubo de seus óculos pelo grupo de Jack, para que pudessem fazer uma fogueira exclusiva. Até então, esse acessório vinha sendo utilizado, um tanto à revelia de Porquinho, para obter fogo pelo direcionamento da luz solar, em benefício de todos. Após o furto, ele afirma: “Vou até ele [Jack] com a concha nas mãos. (...) Saibam, vou dizer: (...) não estou pedindo meus óculos de volta como um favor. (...) [M]as porque o que é certo é certo" (:171). No encontro com Jack e seus aliados, entretanto, uma luta se conforma e a concha, que havia sido uma ideia de Porquinho, se estilhaça. Esse é o segundo acontecimento central a anteceder a morte do personagem, cujo corpo é empurrado do alto de uma pedra.

A trajetória de Porquinho bem evoca tanto o "assassínio direto", quanto o "indireto" motivado pela ampla noção de racismo explorada por Foucault (2005), não restrita à questão da raça, mas sim abarcadora de qualquer alteridade indesejada por um poder hegemônico. $\mathrm{O}$ autor advoga que também constituem espécies de homicídio “.... o fato de expor à morte, de multiplicar para alguns o risco de morte ou, pura e simplesmente, a morte política, a expulsão, a rejeição..." (ibid.:306).

Porquinho encarna assim a "vida nua" problematizada por Agamben (2007) na busca por ampliar tal ótica foucaultiana. A "vida nua" é aquela legitimamente matável por ser considerada sem utilidade e, portanto, não digna de ser vivida. Segundo Agamben (id.), o descortinamento da "vida nua" - que, em última instância, pode ser a de qualquer indivíduo submetido a um poder soberano - torna expostos os limites porosos entre democracia e totalitarismo no modelo de Estado-nação, algo claramente evidenciado pela atuação nazista perante judeus, ciganos, pessoas com deficiência, homossexuais, dentre outras "minorias", cenário que culmina na segunda guerra mundial.

A seu modo, os garotos de $O$ Senhor das Moscas repetem o morticínio do qual fugiam no avião que acabou em queda, pano de fundo este que remete às vivências do autor do livro como combatente durante a segunda guerra (Golding 1984). Exatamente no momento em que os meninos tentam assassinar Ralph, o último dissidente do grupo de Jack, um oficial da marinha acaba os encontrando e fala estupefato: "Eu imaginava que um grupo de meninos britânicos... vocês são britânicos, não é? ... seria capaz de apresentar um espetáculo melhor que esse..." (ibid.:200).

A narrativa de Golding expõe assim as fissuras de um projeto civilizador e aponta para uma crise de práticas de governo ocidentais constituídas no século XIX, sobre a qual se tratará a seguir.

\section{TERCEIRA NARRATIVA: FILHOTE DE CRUZ-CREDO}

Como mencionado, o livro Filhote de Cruz-credo: a triste história alegre de meus apelidos foi empregado pelo governo gaúcho em 2014 como material de intervenção do projeto "Educar sem Discriminar", voltado ao combate do bullying na rede pública estadual de ensino. A obra, de caráter autobiográfico, é assinada por Fabrício Carpinejar (2014). O escritor conduziu uma série de palestras no âmbito do referido projeto, nas quais sua trajetória infantil operou como mote para tratar da prevenção à intimidação entre crianças e adolescentes. 
A narrativa inicia com a descoberta do jovem Fabrício enquanto um menino feio de nascença. Nesse sentido, é exemplar o trecho em que ele visualiza a própria imagem:

Um dia, o chuveiro estragou, enfrentei o banho frio e o vidro do espelho não ficou embaçado. Tinha sete anos. Observei pela primeira vez, com calma, minha cara no espelho e tomei um susto... (...) Toquei no meu nariz, achei grande demais. Toquei na minha testa, achei comprida demais. Toquei no formato da cabeça, achei oval demais, não era redonda como a dos meus colegas, não era certinha como a dos meus irmãos, não se podia desenhar contornando um pote de geleia com o lápis. Igual a um pneu furado de carro... Havia ainda um queixo pontudo, que não combinava com as orelhas pequenas e a boca menor ainda. Eu descobri que era feio... (ibid.:6)

A história prossegue com uma série de apelidos que o garoto recebe no ambiente escolar, não apenas pela aparência de seu rosto, mas também por chamar a atenção em virtude de outras características: tinha pernas finas como as de um "passarinho", usava botas ortopédicas e trocava letras quando falava. Os colegas chegaram a chamá-lo de "Placenta" e de "Cara de Morcego", mas "Cavalinho de Pau" foi o primeiro apelido a Ihe render fama realmente. Certa vez, o menino levou um tombo e rasgou o uniforme do colégio nas nádegas. A mãe, que costumava remendar a roupa com pedaços de couro, não hesitou e inseriu mais um no local comprometido. Assim, os colegas passaram brincar que Fabrício tinha uma "sela de cavalo no traseiro".

O garoto gostava muito de futebol, mas as botas ortopédicas não lhe permitiam ser muito ágil no esporte. Certo dia, contudo, num jogo da escola, conseguiu fazer um gol. Ficou entusiasmado. Mas logo ouviu: “Panqueca! Panqueca! Panqueca!" (:18). Primeiro, achou que o termo não tinha nada com ele, porém, pouco depois descobriu que sim. Alice, a menina mais bonita da escola, era quem puxava o coro. E assim Cavalinho de Pau virou Panqueca. Certa feita, resolveu tirar satisfação com Alice sobre o apelido e ela explicou a escolha: “Ué, não reparou que sua cara é toda amassada?" (:19).

Contudo, o que acontece depois dessa resposta muda por completo a trajetória do personagem. Ele resolveu levar na esportiva o comentário e disse: "Eu sou panqueca, ótimo, pode me dizer se é com ou sem recheio?" (:20). Na mesma ocasião, Fabrício notou que Alice tinha cabelos nos ouvidos e perguntou se ela não iria ao cabeleireiro para apará-los. Todos os colegas em volta riram e diziam: "Essa foi muito boa Fabrício" (:21). O garoto satisfez-se porque, finalmente, havia ouvido seu nome "fora da lista de chamada". Alice passou a ser "Orelha Cabeluda" e, mais tarde, veio a se tornar a primeira namorada de Fabrício.

A história encerra com uma posição bem-sucedida do personagem-autor, que diz: “Hoje me acho bonito do meu jeito, bem feio" (:22). Essa obra infanto-juvenil pode ser contrastada com $A$ llha de Coral não pelo conteúdo, totalmente diferente em ambas, mas sim por elementos que as estruturam. Ao contrário da história protagonizada pelos três jovens marujos ingleses, a narrativa de Filhote de Cruz-credo é centrada em um único indivíduo, o garoto Fabrício, de modo mais específico, nas emoções dele perante sua autoimagem.

A escola está presente no cenário em que se movimenta o personagem de Fabrício, mas não tem o peso institucional que a pátria, a família e a igreja possuem em $A$ Ilha de Coral. Em Filhote de Cruz-credo, as tensões vividas pelas crianças se encaminham entre elas mesmas, sem a mediação de uma entidade ou de um adulto, de 
modo muito mais parecido com o visto em O Senhor das Moscas, embora sem incidentes trágicos num sentido físico, apenas moral. $\mathrm{O}$ autocontrole na condução das situações emerge assim como fundamental.

Tal quadro de diferenças, que contempla uma obra infanto-juvenil do século XIX e outra do século XXI, permite situar uma passagem entre modos de governamentalidade assinalada por Deleuze (1992). Segundo o autor, as "sociedades disciplinares" do século XIX - termo que se refere às "sociedades de governo" ou "sociedades de normalização" demarcadas por Foucault $(1979 ; 2005)$ - são suplantadas, após a segunda guerra mundial, pelas "sociedades de controle". A partir desse marco, os "meios de confinamento" - a família, a escola, a fábrica, o hospital, o exército, a prisão, etc. - característicos das "sociedades disciplinares" ingressam numa "crise generalizada" e passam a demandar reformas constantes.

Deleuze (id.) afirma que, enquanto os confinamentos atuavam como "moldes" de longo prazo, os controles operam como "modulações" de curta duração, de modo que os indivíduos se veem imersos em um "estado de perpétua metaestabilidade". Nesse processo, por exemplo, a empresa substitui a fábrica, assim como a formação permanente se instala por sobre a escola, num cenário em que a meritocracia individual passa a imperar, em detrimento do desempenho da população como massa. O sistema prisional, por sua vez, soma ao encarceramento tradicional as penas alternativas e o uso de coleiras eletrônicas de monitoramento. O sistema de saúde, por seu turno, abraça a "nova medicina", que não cuida apenas dos enfermos, mas também dos "doentes potenciais e sujeitos a risco". Logo, aparecem em marcha novos processos civilizadores.

Rose (1996 ${ }^{8}$ apud Ong; Collier 2005) confere refinamento a esse quadro, ao posicionar esse forma de governamentalidade, hoje chamada de neoliberal, para além de um sistema político-econômico, mas como uma "racionalidade", que prioriza orientar escolhas de atores formalmente livres, em detrimento de agir por meio de mecanismos institucionalizados de comando e controle, no âmbito de arranjos estatais cada vez mais mínimos. Ong e Collier (2005: 13) complementam: "Ela opera, em outras palavras, de acordo com uma racionalidade de tipo mercadológico. Como tal, tem se mostrado altamente expansiva e móvel"9.

Tais ideias se clarificam na análise acerca da "biologia do controle" conduzida por Rose (2007), a partir de um olhar sobre os Estados Unidos. O autor delimita nesse país a existência de uma política contemporânea de saúde pública para o controle da violência focada no gerenciamento do risco, a qual inclui "iniciativas genética e biologicamente inspiradas", mas não apenas elas. Parece oportuno inserir nesse quadro também as intervenções de coibição do bullying, que têm encontrado nos Estados Unidos um espaço ímpar de florescimento, com reverberações ao redor do mundo ${ }^{10}$.

Segundo Rose (id.), a referida política de saúde pública pauta-se na percepção de uma suposta "epidemia de condutas antissociais, agressivas e violentas" no mundo atual, em meio a uma redução das capacidades de autocontrole, de racionalidade e de bom uso da liberdade nas sociedades neoliberais. Instaura, nesse contexto, um "pânico moral extraordinário", no âmbito do qual pessoas com comportamentos entendidos como indesejáveis passam a representar perigo e a serem "demonizadas". Não obstante, o foco de condenação se volta a sujeitos específicos e não a populações ou raças "degeneradas", de modo a evitar conexões com projetos declaradamente racistas e eugênicos preponderantes em séculos anteriores. 
De modo pragmático, a política em questão aspira ao mapeamento de "anticidadãos", ou seja, de "... indivíduos intratáveis incapazes de governar a si mesmos de acordo com as normas civilizadas de uma sociedade liberal livre..." (:249) ${ }^{11}$. Para tanto, lança mão de várias estratégias: identificação psicogenética de indivíduos de risco; apoio comunitário e familiar para ampliar "imunidades" a essa espécie de pessoa; encaminhamento dos sujeitosproblema a terapias diversas; reclusão permanente nos casos entendidos como irrecuperáveis; identificação de zonas onde o risco revela-se passível de mensuração. Dentre estas últimas, emergem com destaque as escolas, onde crianças e adolescentes podem ser observados, testados e monitorados, não por figuras disciplinares como no passado, mas sim por mecanismos cientificamente respaldados ${ }^{12}$.

Pensar o bullying enquanto um "dispositivo" nessa dimensão, que certamente não se restringe aos Estados Unidos, significa conferir atenção às "composições globais" (Ong e Collier 2005). Segundo os autores, tal noção abrange antropologicamente não

... as mudanças associadas com a globalização em termos de transformações estruturais amplas ou novas configurações da sociedade ou da cultura. Em vez disso, examina uma gama específica de fenômenos que articulam essas mudanças: tecnociência, circuitos de troca lícitos e ilícitos, sistemas de administração ou de governança e regimes éticos ou de valores. (: 4$)^{13}$

Sob tal lógica, o bullying desponta no âmbito de uma "composição global" atual não apenas conectado a uma "biologia do controle" (Rose, op. cit.), mas a outros fenômenos de uma governamentalidade do tipo neoliberal, com repercussões no Brasil e fora dele, os quais exigem um olhar antropológico sinérgico.

Dentre eles, por exemplo, está a medicalização da sociedade que atesta, segundo Biehl (2008), uma pulverização indiscriminada das "mercadorias da ciência psiquiátrica". Tais produtos, mais que tratar enfermidades, têm operado enquanto "tecnologias morais" voltadas a controlar comportamentos atualmente considerados desajustados. Em meio a estes, por exemplo, é possível situar a agressividade entre crianças e adolescentes, muitas vezes associada ao bullying, que tem levado às alturas os índices de medicalização infanto-juvenil (Przytyk 2014).

Nessa mesma direção, é possível ainda citar a "judicialização da vida social" que, conforme explica Fonseca (2010), emerge diante da morosidade das instâncias legislativas democráticas e hoje mobiliza uma série de pessoas em busca de solucionar nos tribunais "os mínimos detalhes de suas interações cotidianas". Tal quadro desencadeia, por exemplo, o estabelecimento de esferas alternativas de resolução de conflitos, como a justiça restaurativa, objeto de análise de Schuch (2012), via pela qual, na atualidade, episódios de bullying já recebem encaminhamento em escolas públicas de Porto Alegre (Justiça para o Século 21 2014).

Diferentemente do judiciário tradicional, focado na punição de culpados, a justiça restaurativa centra-se na administração das subjetividades de todos os envolvidos numa contenda, de maneira a fomentar entre os sujeitos a autorresponsabilização e a autodisciplina em prol da não violência, princípios caros, como visto, à governamentalidade neoliberal. Percebe-se, portanto, que os referidos fenômenos, que podem não indicar claras associações de saída, encontram-se interconectados. A acepção de "composição global", enquanto "conceito compósito", permite assim apreendê-los em suas múltiplas determinações, dinamicidades e tensões (Ong; Collier 2005). 


\section{ALGUMAS CONSIDERAÇÕES À LUZ DA ETNOGRAFIA}

Na seção precedente, a narrativa infanto-juvenil Filhote de Cruz-credo, cotejada à história de $A$ I/ha de Coral, auxiliou especialmente na visualização das complexidades em torno da passagem de um modelo de governamentalidade de gênero disciplinar para outro de caráter neoliberal. No presente tópico, Filhote de Cruz-credo servirá enquanto fio condutor para aprofundar alguns traços distintivos do bullying como "dispositivo" integrante de um modo neoliberalista de governo, tendo em vista que a obra sintetiza conclusões preliminares da etnografia de conteúdo midiático que venho desenvolvendo ${ }^{14}$.

Tal investimento, uma das frentes em estágio mais avançado de minha pesquisa de doutoramento, compreende a leitura e sistematização diária de materiais de imprensa. Essa tarefa lastreia-se na perspectiva de Vianna (2014), segundo a qual documentos, como as reportagens jornalísticas, atuam como "produtores de realidade" e constituem, portanto, "peças etnográficas" tão relevantes quanto quaisquer outras.

Nesse esforço, busca-se por algo que Fonseca (1999) assinala como fundamental à empreitada antropológica: a identificação de "sistemas", com capacidade de transcender casos individuais. Isso pressupõe o registro cotidiano do andamento da cobertura midiática em diários de campo, com o propósito de identificar, paulatinamente, regularidades na abordagem do bullying pelos meios de comunicação. Essas recorrências dignas da atenção antropológica são objeto de discussão a seguir, porquanto amplificam a reflexão já empreendida aqui em torno do bullying a partir de narrativas ficcionais, estas também documentos a produzir "realidades" (Vianna, op. cit.).

A exemplo da narrativa da obra Filhote de Cruz-credo, a cobertura da imprensa ocidental acerca do bullying dá amostras de uma tensão entre dois princípios centrais, ao menos em teoria, à operacionalidade das democracias contemporâneas: a promoção da igualdade versus a valorização da diversidade entre os indivíduos. Deleuze (1987:142) problematiza esse conflito quando afirma:

A luta por uma subjetividade moderna passa por uma resistência às duas formas actuais [sic] de sujeição, uma que consiste em individuar-nos de acordo com as exigências do poder, e outra que consiste em prender cada indivíduo a uma identidade sabida e conhecida, bem determinada de uma vez por todas. A luta pela subjetividade apresenta-se então como direito à diferença, e como direito à variação, à metamorfose.

Nesse sentido, a partir de um slogan recorrente - "Bullying não é brincadeira" -, as recomendações moralizantes presentes no conteúdo midiático têm procurado destacar, paradoxalmente, a necessidade de respeitar as diferenças porque todos os indivíduos seriam iguais enquanto cidadãos. Tal esforço de divulgar a importância de aceitação da alteridade, entretanto, não contempla, nem sequer superficialmente, o contexto sociológico que determina a intolerância e, consequentemente, a violência.

Verifica-se que as matérias dos veículos de comunicação vêm se concentrando prioritariamente em histórias de indivíduos que, em geral, estiveram na posição de vítimas de bullying e possuem uma trajetória de "superação" entendida como dotada de carga noticiosa. Ao retratar esses itinerários pessoais, os relatos midiáticos enfatizam princípios típicos da governamentalidade neoliberal, como o autocontrole e a autodisciplina, os quais se revelam fundamentais à saída da condição de vitimização. A contextura social dos personagens é, por conseguinte, suspensa. 
Tal cobertura ocorre assim em detrimento da abordagem daquilo que Fassin (2009) denomina por "desigualdades", assentadas em disparidades sociais, econômicas, étnico-raciais, de gênero, de orientação sexual, de padrões estéticos, dentre outras, as quais se encontram intrinsecamente conectadas a práticas de violência na atualidade. Segundo o autor, é possível aproximar formas tão diferentes de desigualdades porque todas elas dizem respeito a vidas corporificadas que valem menos perante outras que valem mais no presente status quo.

Em análise sobre a forma como a epidemia de Aids na África do Sul tem sido trabalhada pela imprensa ocidental, Fassin (2007) afirma que, ao focar na doença circunscrita aos limites territoriais desse país, a mídia desconsidera que a história de tal enfermidade nessa região do mundo fala de uma "ordem política mundial", composta de "configurações sociais", "relações de conhecimento e poder" e "discursos sobre o outro".

Nessa mesma direção, parece plausível afirmar que, enquanto a imprensa vem se restringindo a abordar episódios de bullying como enfrentamentos entre indivíduos atomizados, o acompanhamento etnográfico detido da cobertura midiática desvela a existência de pessoas mais propensas a se tornarem vítimas de violência moral, em virtude de um quadro planetário de profundas e diversificadas desigualdades estruturais.

Nesse apanhado de histórias compreendidas limitadamente como empreitadas individuais, os veículos de comunicação de massa têm conferido destaque a experiências de bullying vivenciadas especialmente na infância ou adolescência por pessoas hoje famosas e, portanto, teoricamente bem-sucedidas graças a seus próprios esforços em deixar a condição de vitimização ${ }^{15}$. A obra Filhote de Cruz-credo é ilustrativa nesse sentido, visto que se alicerça no percurso infanto-juvenil do menino Fabrício, hoje um reconhecido escritor gaúcho.

Para além desse viés, são valorizadas midiaticamente histórias de indivíduos anônimos que, uma vez tendo reconhecido a autorresponsabilidade pelo bullying sofrido, alavancam pela via da autodisciplina mudanças em si próprios, adequadas a padrões hegemônicos que funcionam como escudos à violência. Nesse sentido, são emblemáticos os casos de pessoas obesas que lançam mão de dietas rígidas em busca não só do emagrecimento saudável, mas também de uma forma física escultural culturalmente valorizada no Ocidente e, de modo específico, no Brasil ${ }^{16}$.

Assim como no desfecho da obra Filhote de Cruz-credo, em que as desavenças vividas pelas crianças se resolvem entre elas mesmas, com praticamente nenhuma intervenção institucional, os testemunhos midiáticos de vítimas de bullying têm ressaltado que a superação da violência pode depender apenas de investimentos advindos delas próprias. Por trás disso, visualizam-se arranjos estatais mínimos que indicam lançar mão do "dispositivo" do bullying para obscurecer desigualdades e violências cuja escala, em realidade, não é individual, mas sociocultural.

No contexto da cobertura de imprensa sobre o bullying, percebe-se, por conseguinte, o valor do "ato de testemunhar" que, conforme defende Das (2011), atua como uma forma ímpar de trabalhar a "relação entre violência e subjetividade". Nesse sentido, é importante destacar os testemunhos contra-hegemônicos que, graças às potencialidades atuais das mídias colaborativas, vêm desafiando o formato dos depoimentos prevalecentes na mídia convencional. 
Um exemplo interessante reside nos vídeos-testemunhos de vítimas de bullying que têm se tornado virais na internet ${ }^{17}$. Tais materiais lembram as feições das "self-narratives" on-line evocadas por Rose e Novas (2005), quando abordam a elaboração da "cidadania biológica" por parte de portadores de doenças graves. Dizem os autores que "... essas narrativas fornecem técnicas para nortear a vida em face da doença. (...) [E]sses vetores 'de baixo' pluralizam a verdade biológica e médica, introduzindo dúvida e controvérsia e realocando a ciência nos domínios da experiência, da política e do capitalismo" (:14 $)^{18}$.

De um lado, tais testemunhos, que denominei contra-hegemônicos, demonstram o agenciamento permanente dos sujeitos em torno dos "dispositivos", os quais estão assim longe de ser meramente impostos ou de tomarem uma forma acabada. Ortner (2007:76) advoga que a capacidade de "agência" pressupõe a busca de "... objetivos e fins culturalmente significativos, sejam estes para o bem ou para o mal". Considerada essa premissa, de outro lado, depreende-se da etnografia midiática sobre o bullying que a nominação e a tipificação da intimidação moral - que não é um fenômeno novo, mas que num passado recente, não detinha uma denominação específica cientificamente autorizada - também pode municiar os indivíduos para a violência, tornando assim opacas as fronteiras entre vítimas e agressores.

Na narrativa de Filhote de Cruz-credo, tal quadro fica perceptível: o desfecho vitorioso do menino Fabrício, injuriado ao longo da história, demarca-se no momento em que ele apelida a menina Alice de "Orelha Cabeluda", a qual vem a ser mais tarde sua namorada. A cobertura midiática sobre o bullying contempla igualmente tal troca de posições ao conferir ênfase à "vingança"19. Ou seja, a existência de vendeta da vítima - que, no limite, a torna agressora - amplia a carga noticiosa do testemunho.

Tal intercâmbio de status faz evocar a abordagem de Elias (1997) sobre "surtos descivilizadores" com base no conceito batesoniano de "duplo vínculo". Segundo o autor, trata-se de um quadro de confronto crescente entre "estabelecidos" e "outsiders", no qual "...a violência engendra a contraviolência, a contraviolência aumenta a violência do outro lado, e assim por diante" (:183). Embora não seja possível delimitar o marco inicial desse processo, este sinaliza uma "tendência para a autoescalada".

A abordagem da imprensa acerca do bullying não apenas evidencia as posições fluidas de agredidos e agressores, como também demonstra fronteiras atualmente borradas entre o insulto e a jocosidade, esta última uma temática antropológica clássica. Sob o mote do bullying, têm sido noticiados episódios bastante díspares, desde brincadeiras classificadas como de bom ou de mau tom a casos de suicídio e homicídio ${ }^{20}$.

Segundo Gay (2001), uma das marcas do processo civilizatório do século XIX foi o extenso volume de especulações e filosofias produzidas sobre as motivações em torno do riso. Conforme o autor, essa foi uma das vias pelas quais emotividades odiosas e agressivas puderam ser "sublimadas" nesse período. Do século XX em diante, todavia, diante da emergência do autocontrole caro à governamentalidade neoliberal, os limites entre humor e violência demonstram-se cada vez mais tênues e difíceis de estabelecer. Verifica-se assim a delimitação de um contexto que coloca em xeque a eficácia do chiste como um "antirrito", o qual, no sentido atribuído por Douglas (1993), guarda uma capacidade ímpar de desorganizar e subverter estruturas de poder hegemônicas. 


\section{CONSIDERAÇÕES FINAIS}

O presente artigo buscou pensar o bullying enquanto um "dispositivo" no sentido foucaultiano, auxiliado pela literatura antropológica do campo da governamentalidade, bem como pela noção de "processo civilizador" de Elias (1997). Para tanto, serviu-se de outro "dispositivo", a literatura, especialmente a voltada ao público infanto-juvenil. Por meio do exercício comparativo entre modos de governamentalidade, propiciado por conteúdos literários datados, esforço este atrelado a reflexões oriundas de uma etnografia midiática em andamento, o artigo procurou identificar condições e motivações pelas quais, na contemporaneidade, práticas tipificadas como bullying se tornam, para usar uma expressão de Foucault (1984), "objeto de uma preocupação moral".

A análise apontou que o bullying encontra-se ancorado em um modo de governo do tipo neoliberal, no qual prevalece o Estado mínimo e se enaltece a autodisciplina, o autocontrole e a autorresponsabilidade dos cidadãos como vias principais para assegurar a não violência. Contudo, uma vez criado e sob agência dos sujeitos, o referido "dispositivo" tem exercido um duplo e contraditório papel: de coibir a agressividade especialmente moral e, paradoxalmente, de promovê-la, na medida em que concede a ela um nome, assim como características distintivas.

Sob tal lógica, indivíduos são todos potencialmente vítimas ou agressores, muito embora alguns estejam suscetíveis a essa primeira condição pelo fato de ocuparem posições subalternas num quadro em que prevalecem enormes desigualdades nacionais e mundiais de ordem social, econômica, étnica, dentre outras. Tal panorama, contudo, é obscurecido - assim como o racismo, num sentido amplo, foucaultiano, aqui abordado - quando se situa o bullying como uma questão de enfrentamento entre indivíduos tão somente, sem intercorrência ou responsabilidade de quaisquer outras instâncias.

Diante de tais constatações coloca-se oportuno o questionamento de Rose (2007), a fim de pensar com criticidade as "micropolíticas das práticas contemporâneas de controle": quais são os benefícios, os perigos, os ganhos e os custos dessas intervenções e para quem? Interrogações dessa natureza revelam-se fundamentais para descentrar uma discussão pública que tem se restringido em evidenciar as benesses do combate ao bullying, em detrimento do debate em torno das contradições e tensões que permeiam a operacionalidade cotidiana desse "dispositivo". Aqui vale lembrar o alerta de Foucault (2006:267) de que toda "... liberação abre um campo para novas relações de poder, que devem ser controladas por práticas de liberdade". 


\section{NOTAS}

1 Atualmente, fala-se, por exemplo, em bullying corporativo, bullying esportivo, bullying familiar e bullying político, especialmente na cobertura midiática, mas também em matérias do legislativo no Brasil (Câmara dos Deputados 2014; Senado Federal 2014).

2 Agradeço a Patrice Schuch pelas instigantes interlocuções para a elaboração deste artigo, no âmbito do curso Práticas de Governo, Cultura e Subjetividade do PPGAS/UFRGS. Também sou grata aos pareceristas deste periódico, cujas considerações metodológicas e textuais foram da maior valia para a versão final.

3 Na tradução de $A$ I/ha de Coral para o português, o nome Rodolfo Rover foi aplicado ao protagonista em substituição à Ralph Rover, presente no original. Além disso, na versão britânica da obra, os dois amigos desse personagem se chamam Jack Martin e Peterkin Gay. Tais fatos são dignos de nota porque em O Senhor das Moscas, William Golding denomina os dois protagonistas de sua história igualmente de Ralph e Jack, um dos elementos a dar evidência da relação estabelecida entre a narrativa dele e aquela de $A$ /lha de Coral.

4 O Estado percursor nesse panorama foi Santa Catarina, com a Lei n. 14.651, de 2009 (Pádua 2014).

5 O esforço etnográfico no campo midiático iniciou em 2013 e se intensificou ao longo de 2014 e de 2015. Tem se dado, prioritariamente, sob auxílio da ferramenta de alertas do Google, responsável por enviar atualizações diárias de conteúdos da Internet que contenham palavras-chave previamente cadastradas. Uma parte do resultado desse trabalho, que compreende filtrar e pensar criticamente materiais de imprensa nacional e internacional, está exposta como uma subseção da bibliografia deste artigo. Nesse tópico, ocorre a apresentação de um apanhado de referências midiáticas que se relacionam com questões abordadas ao longo do presente texto.

6 Inevitável neste ponto não rememorar as análises antropológicas de Sahlins (2003) acerca da conquista inglesa do território havaiano, comandada pelo Capitão Cook.

7 Importa assinalar que o rico conteúdo da obra de Golding já serviu de mote para diversas análises acadêmicas, tanto de um ponto de vista literário, quanto de outras áreas do conhecimento. Nesse sentido, cf. Silva (2008), Botelho (2012), Belo (2011) e Santos (2013), para alguns exemplos recentes.

8 ROSE, Nikolas. 1996. “Governing 'advanced' liberal democracies". In: N. Rose, A. Barry \& T. Osborne (eds.). Foucault and political reason: liberalism, neo-liberalism, and rationalities of government. London: UCL Press.

9 Tradução minha; grifo do original.

10 Por exemplo, cf. Bully (2011).

11 Tradução minha.

12 Para um exemplo nessa direção no contexto brasileiro, cf. Santos e Primi (2014).

13 Tradução minha.

14 Para retomar detalhes, cf. nota 5.

15 Nesse sentido, cf. os seguintes exemplos na seção reservada às Referências de Mídia: Globo.com (2015), Marie Claire (2014), O Globo (2015) e Showbizz (2014).

16 Cf. os seguintes exemplos na seção de Referências de Mídia: G1 Itapetininga (2014) e Henriques (2014).

17 Cf. os seguintes exemplos na seção de Referências de Mídia: Portal Forum (2013) e Garoto de 12 anos desabafa sobre bullying homofóbico (2013).

18 Tradução minha.

19 Cf. os seguintes exemplos na seção de Referências de Mídia: Bastos (2014) e Correio (2014).

20 Cf. os seguintes exemplos na seção de Referências de Mídia: Ferreira (2014), Globo.com (2014), Paraiba.com.br (2014) e Terra Notícias (2014). 


\section{REFERÊNCIAS BIBLIOGRÁFICAS}

ABU-LUGHOD, Lila. 2003. “Melodrama egípcio: uma tecnologia do sujeito moderno?” Cadernos Pagu 21: 75-102.

AGAMBEN, Giorgio. 2005. “O que é um dispositivo?" Outra Travessia 5: 9-16.

2007. Homo Sacer: o poder soberano e a vida nua. Belo Horizonte: Editora da UFMG.

BALLANTYNE, Robert. 1858. The Coral Is/and: a tale of the Pacific Ocean. Recuperado em nov. 2014, de http://migre. $\mathrm{me} / \mathrm{nIXP} 4$. Tecnoprint.

1970. A Ilha de Coral. Recontado em português por Nélida Piñon. Coleção 12 anos. Rio de Janeiro: Editora

BECKER, Howard. 2008 [1963]. Outsiders: estudo de sociologia do desvio. Rio de Janeiro: Jorge Zahar Ed.

BELO, Fábio. 2011. "O animal na obra de Freud: uma leitura de 'O Senhor das Moscas'”. In: J. N. M. Coutinho (org.). Direito e psicanálise: interlocuções a partir de "O Senhor das Moscas" de William Golding. Rio de Janeiro: Lumen Juris.

BIEHL, João. 2008. "Antropologia do devir: psicofármacos - abandono social - desejo". Revista de Antropologia 51(2): 413-449.

BOTELHO, Inês. 2012. “No início e no fim: da utopia, eutopia e distopia em 'Lord of the Flies' e nas suas adaptações cinematográficas". E-topia Revista Electrónica de Estudos sobre a Utopia 13.

BOURDIEU, Pierre. 2003a. "A gênese dos conceitos de habitus e de campo". In: O poder simbólico. Rio de Janeiro: Bertrand Brasil.

2003b. "Algumas propriedades dos campos". In: Questões de sociologia. Lisboa: Fim de Século.

BULLY. Lee Hirsch. Estados Unidos, 2011. 99 min, cor. Documentário audiovisual.

CÂMARA DOS DEPUTADOS. Projetos de lei e outras proposições. Recuperado em nov. 2014, de www.camara.leg.br.

CARPINEJAR, Fabrício. Filhote de Cruz-credo: a triste história alegre de meus apelidos. Recuperado em set. 2014, de http://migre.me/nIXRm.

DAS, Veena; POOLE, Deborah. 2008. "El estado y sus márgenes: etnografías comparadas". Revista Académica de Relaciones Internacionales 8.

DAS, Veena. 2011. "O ato de testemunhar: violência, gênero e subjetividade". Cadernos Pagu 37: 9-41.

DELEUZE, Gilles. 1987. "As dobras, ou o de dentro do pensamento (subjectivação)". In: Foucault. Lisboa: Vega. 1992. "Post-scriptum sobre as sociedades de controle". In: Conversações:1972-1990. Rio de Janeiro: Editora 34. 1996. “O que é um dispositivo?" In: O mistério de Ariana. Lisboa: Vega.

DOUGLAS, Mary. 1993. “Jokes”. In: Implicit meanings: essays in anthropology. London: Routledge \& Kegan Paul.

ELIAS, Norbert. 1997. Os alemães: a luta pelo poder e a evolução do habitus nos séculos XIX e XX. Rio de Janeiro: Jorge Zahar Ed.

FASSIN, Didier. 2007. “Conclusion: this world we live in". In: When bodies remember: experiences and politics of Aids in South Africa. Berkeley, Los Angeles: University of California Press. 
2009. "Another politics of life is possible". Theory Culture Society 26(5): 44-60.

2013. Enforcing order: an ethnography of urban policing. Cambridge: Polity Press.

FONSECA, Claudia. 1999. “Quando cada caso não é um caso: pesquisa etnográfica em educação". Revista Brasileira de Educação, São Paulo, 10: 58-78.

2010. “'Ordem e progresso' à brasileira: lei, ciência e gente na 'co-produção' de novas moralidades familiares”. In: J. Ferreira \& P. Schuch (orgs.). Direitos e ajuda humanitária: perspectivas sobre gênero, família e saúde. Rio de Janeiro: Editora da Fiocruz.

FOUCAULT, Michel. 1979. "A governamentalidade". In: Microfísica do poder. Rio de Janeiro: Edições Graal.

1984. "Introdução". In: História da sexualidade 2: o uso dos prazeres. Rio de Janeiro: Graal.

. 2005. "Aula de 17 de março de 1976". In: Em defesa da sociedade. São Paulo: Martins Fontes.

2006. "A ética do cuidado de si como prática da liberdade". In: Ética, sexualidade e política. Rio de Janeiro: Forense Universitária.

GAY, Peter. 2001. O cultivo do ódio: a experiência burguesa da rainha Vitória a Freud. São Paulo: Companhia das Letras. GOLDING, William. 1984. O Senhor das Moscas. São Paulo: Abril Cultural.

HANNERZ, UIf. 2003. "Being there... and there... and there! Reflections on multi-site ethnography". Ethnography 4(2): 201-216.

JUSTIÇA PARA O SÉCULO 21. Justiça restaurativa contra o bullying. Recuperado em set. 2014, de http://migre.me/nIXTY. LORD OF FLIES. Peter Brook. Inglaterra, 1963. 90 min, PB. Audiovisual.

MARCUS, George. 1995. "Ethnography in/of the world system: the emergence of multi-sited ethnography". Annual Review of Anthropology 24: 95-117.

ONG, Aiwa; COLLIER, Stephen (orgs.). 2005. "Global assemblages, anthropological problems". In: Global assemblages: technology, politics and ethics as anthropological problems. Oxford: Blackwell Publishing.

ORTNER, Sherry. 2007. “Poder e projetos: reflexões sobre a agência”. In: M. P. Grossi, C. Eckert \& P. Fry (orgs). Conferências e diálogos: saberes e práticas antropológicas. Blumenau: Nova Letra.

PÁDUA, Caio de. 2014. "Bullying": panorama jurídico e legis/ação aplicável. Recuperado em ago. 2015, de http://jus. com.br/artigos/28324/bullying-panorama-juridico-e-legislacao-aplicavel\#ixzz3hUUtyvvG.

PRZYTYK, Mariana. 2014. “Uso de remédio para déficit de atenção cresceu 775\% em 10 anos”. Câmara Notícias. Recuperado em set. 2014, de http://migre.me/nFzYO.

RIO GRANDE DO SUL. 2010. “Lei n. 13.474. Dispõe sobre o combate da prática de 'bullying' por instituições de ensino e de educação infantil, públicas ou privadas, com ou sem fins lucrativos". Diário Oficial 121.

ROLIM, Marcos. 2008. Bullying: o pesadelo da escola. Um estudo de caso e notas sobre o que fazer. 174 f. Dissertação de Mestrado. Porto Alegre: Universidade Federal do Rio Grande do Sul.

ROSE, Nikolas. 2007. "The biology of control". In: The politics of life itself: biomedicine, power and subjectivity in the twenty first century. Princeton: Princeton University Press. 
ROSE, Nikolas; NOVAS, Carlos. 2002. Biological citizenship. Recuperado de http://thesp.leeds.ac.uk/files/2014/04/ RoseandNovasBiologicalCitizenship2002.pdf.

SAHLINS, Marshall. 2003. Ilhas de história. Rio de Janeiro: Zahar.

SANTOS, Daniel; PRIMI, Ricardo. 2014. Desenvolvimento socioemocional e aprendizado escolar: uma proposta de mensuração para apoiar políticas públicas. São Paulo: OCDE; Instituto Ayrton Senna; Secretaria de Educação do Governo do Rio de Janeiro.

SANTOS, Ricardo Maria dos. 2013. "Simon e as marcas do sagrado em 'O Senhor das Moscas', de William Golding". In: Simpósio Internacional de Letras e Linguística - SILEL. Anais... Uberlândia: EDUFU.

SCHUCH, Patrice. 2012. "Justice, culture and subjectivity". Vibrant 9: 34-69.

SENADO FEDERAL. Atividade legis/ativa. Recuperado em nov. 2014, de www.senado.gov.br.

SILVA, Nivaldo Correia. 2008. "Entre o possível e o imaginado: controle social, ficção e realidade". Tópos 2(1): 107-122.

VIANNA, Adriana. 2014. "Etnografando documentos: uma antropóloga em meio a processos judiciais." In: S. R. R. Castilho, A. C. de Souza Lima \& C. C. Teixeira (orgs.). Antropologia das práticas de poder: reflexões etnográficas entre burocratas. Rio de Janeiro: Contra Capa.

\section{REFERÊNCIAS DE MÍDIA}

AGRA, Marcela. 14 nov. 2014. Não é brincadeira: como o "bullying corporativo" destrói profissionais e empresas. Recuperado em nov. 2014, de http://migre.me/nsBjH.

BASTOS, Giuline. 17 dez. 2014. Isabeli Fontana diz ter sofrido bullying: 'O sucesso é a maior vingança'. Recuperado em dez. 2014, de http://migre.me/nOgD5.

CORREIO. 06 dez. 2014. Jovem vítima de bullying 'se vinga' e dá fora em colega 10 anos depois. Recuperado em dez. 2014, de http://migre.me/nlYEJ.

FERREIRA, Rafael. 12 dez. 2014. Mark Zuckerberg teme que um botão 'não curti' gere bullying no Facebook. Recuperado em dez. 2014, de http://migre.me/nOfq4.

GAROTO DE 12 ANOS DESABAFA SOBRE BULLYING HOMOFÓBICO. 24 maio 2013. Recuperado em out. 2013, de http:// migre.me/fhzEf.

GAZETA PRESS. 04 dez. 2014. Corredor de 1,46m desafia bullying e agressões por $10^{a}$ São Silvestre. Recuperado em dez. 2014, de http://migre.me/nlYqc.

GLOBO.COM. 02 dez. 2014. Bullying olímpico: Sarah Menezes dá apelido aos mascotes do Rio 2016. Recuperado em dez. 2014, de http://migre.me/nlYnw.

GLOBO.COM. 11 jan. 2015. Victor, dupla de Leo, lembra poemas que fazia na escola: 'Sofria bullying'. Recuperado em jan. 2015, de http://migre.me/o5yNe.

G1 ITAPETININGA. 22 nov. 2014. 'Fracasso' com meninas faz jovem emagrecer e querer ser fisiculturista. Recuperado 
em nov. 2014, de http://migre.me/nlYbW.

HENRIQUES, Camila. 21 dez. 2014. Após bullying, jornalista emagrece $36 \mathrm{~kg}$ com dieta e pole dance no AM. Recuperado em dez. 2014, de http://migre.me/nOheS.

MARIE CLAIRE. 29 nov. 2014. "Sofro bullying virtual até hoje: me chamam de sapatão, dizem que sou homem", diz Rebeca Gusmão. Recuperado em nov. 2014, de http://migre.me/nOhCK.

O GLOBO. 09 jan. 2015. Thaila Ayala diz que bullying sofrido no colégio ajudou a compor nova personagem. Recuperado em jan. 2015, de http://migre.me/o5yDX.

O NACIONAL. Estado começa série de palestras sobre bullying. Recuperado em set. 2014, de http://migre.me/nIXUA.

PARAIBA.COM.BR. 16 dez. 2014. Mãe de serial killer da Baixada Fluminense diz que filho sofria bullying na escola. Recuperado em dez. 2014, de http://migre.me/nOg4L.

PORTAL FORUM. Reação de aluno ateu a bullying acaba com pai-nosso na escola. Recuperado em out. 2013, de http:// migre.me/fac90.

SHOWBIZZ, Bang. 10 dez. 2014. Paul Stanley sofreu bullying quando criança. Recuperado em dez. 2014, de http://migre. me/nOeLf.

TERRA NOTÍCIAS. 27 ago. 2014. Criança se mata após bullying e pais divulgam fotos. Recuperado em ago. 2014, de http://migre.me/nIXEh. 


\section{Uma reflexão sobre bullying e governamentalidade a partir de três narrativas de ficção}

\section{RESUMO}

O presente artigo busca pensar o construto científico do bullying enquanto um "dispositivo" no sentido foucaultiano, auxiliado pela literatura antropológica do campo da governamentalidade, bem como pela noção de "processo civilizador" de N. Elias. Para tanto, serve-se de outro "dispositivo", a literatura, especialmente a voltada ao público infanto-juvenil. Por meio do exercício comparativo entre modos de governamentalidade, propiciado por conteúdos literários datados, esforço este atrelado a reflexões oriundas de uma etnografia midiática em andamento, o artigo procurou identificar condições e motivações pelas quais, na contemporaneidade, práticas tipificadas como bullying, que indubitavelmente não são novas, se tornam "objeto de uma preocupação moral", para usar uma expressão foucaultiana.

PALAVRAS-CHAVE: Bullying; processos civilizadores; governamentalidade.

\section{A reflection about bullying and governmentality based on three fictional narratives}

\section{ABSTRACT}

This article seeks to think the scientific construct of bullying as a "device" in Foucault's sense, aided by the anthropological literature of governmentality field, as well as the notion of "civilizing process" from N. Elias. Therefore, it serves up from another "device", the literature, especially focused on children and youth. Through comparative exercise between modes of governmentality fostered by dated literary content, this effort linked to reflections coming from a media ethnography in progress, the article aims to identify conditions and motivations why, in contemporary times, typified practices as bullying, which undoubtedly not are new, become "the object of a moral concern", to use Foucault's expression.

KEYWORDS: Bullying; civilizing processes; governmentality.

Recebido em: 28/08/2015

Aprovado em: 09/11/2016 